Vargas-Callejas, G., M. Barba-Núñez, A. Carvalho, M. Vicente-Mariño, M. Arto-Blanco \& P. A. Meira-Cartea (2018) 'How do university students perceive and evaluate responses to climate change?', The International Journal on Climate Change: Impacts and Responses, 10 (2), 1-19. DOI: https://doi.org/10.18848/1835-7156/CGP/v10i02/1-19

\title{
How do students perceive and evaluate responses to climate change?
}

Germán Vargas-Callejas, Associate Professor, Department of Pedagogy and Didactics, Universidade de Santiago de Compostela, Santiago de Compostela, Spain

María Barba-Núñez, Researcher, Department of Pedagogy and Didactics, Universidade de Santiago de Compostela, Santiago de Compostela, Spain

Anabela Carvalho, Associate Professor, Department of Communication Sciences, Universidade do Minho, Braga, Portugal

Miguel Vicente-Mariño, Associate Professor, Department of Sociology and Social Work, Universidad de Valladolid, Segovia, Spain

Mónica Arto-Blanco, Researcher, Department of Pedagogy and Didactics, Universidade de Santiago de Compostela, Santiago de Compostela, Spain

Pablo Ángel Meira-Cartea, Associate Professor, Department of Pedagogy and Didactics, Universidade de Santiago de Compostela, Santiago de Compostela, Spain

Impacts of climate change are increasingly felt in our daily lives. Although scepticism is still found among certain social groups, most lay discourses show awareness of the current environmental challenges. In order to move forward and develop action plans to mitigate and adapt to climate change, young people are an important voice to be heard.

This research article tackles questions pertaining to the relation between climate change communication, education and social perception of science, exploring social and cultural representations of climate change through the discourses of young people. Fieldwork involved eight focus groups conducted in Brazil, Mexico, Portugal and Spain with a total of 50 higher education students of Experimental/Natural Sciences and Engineering, and of Social Sciences and Humanities. Discussions were organized around 16 images referring to the causes, consequences and responses to climate change.

Without significant differences between knowledge areas or countries, findings point to awareness of multiple types of responses to climate change, even though students' analyses were more grounded on common culture than on solid scientific evidence and language. Adaptation strategies were more rarely mentioned than mitigation actions. A strong emphasis was put on barriers to response implementation. Moderate optimism regarding some possible responses was impaired by distrust regarding the political and economic systems leading to calls for transformation at multiple levels.

Keywords: Climate Change, Social Representations, Higher Education, Focus Groups, Comparative Studies 


\section{INTRODUCTION}

Scientific evidence has unequivocally shown the occurrence of anthropogenic climate change, which is one the greatest challenges to the current century. Reports from the Intergovernmental Panel on Climate Change (IPCC) and several public institutions have brought together responses to a changing climate focused on two fundamental notions: mitigation and adaptation. While mitigation seeks to reduce emissions or enhance greenhouse gas sinks, adaptation aims to reduce or avoid damages or to take advantage of opportunities considered as beneficial (IPCC 2014). The IPCC has also made significant advances in the development of future scenarios. Different scenarios have been considered based on hypothetical global mitigation trajectories, which are connected to foreseeable adaptation needs. In all of them, the interactions between socio-economic processes and changes in the climate system are clear, both in terms of accelerating or reducing the consequences of climate change.

Scientific research has clarified the origin and consequences of climate change, but the main source of uncertainty lies in the social, economic, political and technological responses that will be chosen to address this threat. So far, in the absence of profound transformations in energy production and consumption, the greenhouse gas emissions pathway seems to be oriented toward higher temperature scenarios. If we focus on national realities, we find that countries face different challenges and circumstances. This is evident in the four countries involved in this project: Brazil, Mexico, Portugal and Spain. All of them have ratified the Paris Agreement, but figures show different starting points. Regarding causal responsibility, the two European countries are the ones producing most emissions per capita. Spain (5.1 tones) produces double the greenhouse emissions of Brazil (2.5 tones) while Portugal (4.4 tones) and Mexico (3.9 tones) present smaller differences (UNDP 2017). Spain and Portugal have a very high Human Development Index (HDI), whereas Brazil and Mexico reach a high HDI, affecting their vulnerability and capacity to mitigate their emissions and adapt to risks.

The development of responses to climate change require not only that people are aware of it but also consider it a pressing problem, demand effective policies and are willing to adopt significant changes in their daily lives. Research has shown that public concern with the climate crisis has disseminated around the world (Capstick et al. 2015). Several scholars have used the theory of social representations to explain how climate change is re-worked from a lay person's perspective (Correa 2012; Fischer 2012; Moloney et al. 2014; González-Gaudiano and Maldonado-González 2013; Meira et al. 2013; Smith and Hoffe 2012). According to this theory, a phenomenon originating in the field of science - climate change -, becomes a constitutive element of common knowledge through psychosocial and cultural processes. At the cognitive level, the process of transposition involves dynamics of objectivation, converting what is abstract into something concrete, and the anchoring of the phenomenon in the system of preexisting categories (Wagner and Hayes 2011). This renders the phenomenon of climate change understandable by integrating it into social reality.

Various media - mainly mass media - and mediators from different fields (journalists, politicians, scientists, ecologists, teachers, etc.) intervene in the social representation process. In addition, it is worth noting that representations have a linguistic dimension, and are expressed through concepts, images and metaphors (Wagner and Hayes 2011). Research methodologies on social representations have included questionnaires, in- 
depth interviews and focus groups to investigate how a particular group represents an issue. Studies using conceptual and narrative elements, together with the iconography of climate change as a discursive element, have so far been scarce, either applying the theory of social representations (Smith and Joffe 2012) or other conceptual frameworks (Leiserowitz 2006; O'Neill and Nicholson-Cole 2009).

Research drawing on different theoretical frameworks suggests that public views on climate change are nuanced. Diverse individual and collective barriers that modulate perception have been identified, turning climate change into a recognized threat, but also an abstract one, which is considered far away from everyday priorities (Lorenzoni, Nicholson-Cole and Whitmarsh 2007; Moser and Dilling 2007). People in different countries associate climate change predominantly with negative issues and catastrophes while responses to the problem remain on a secondary level (Leiserowitz 2006; Meira et al. 2013). These traits have also been detected in studies focusing on Mexican (González-Gaudiano and Maldonado-González 2013), Portuguese (Cabecinhas, Lázaro and Carvalho 2006), and Spanish university students (Meira and Arto 2014). However, catastrophic views seem less marked among young Germans and Americans compared to older age groups (Corner et al 2015).

Over the last few decades, climate change has been incorporated in currricula at different levels of school education. Despite an educational effort, studies conducted in different countries show that basic scientific concepts related to climate change remain largely unknown to young people (Corner et al 2015). Even at the university level, deficiencies in the understanding of climate change have been found among students of different programmes (Wachholz, Artz and Chene 2012). Morgado et al. (2017) have argued that representations, as well as actions, of university students in relation to climate change are heavily influenced by social and cultural factors to the detriment of specialized training.

This article brings together questions related to climate change communication, higher education and social representations of science. The discourses of university students about social, economic, political and technological responses to face climate change are explored with the aim of analysing, from a cross-national comparative perspective, the influence of scientific training and of the cultural frameworks in which social representations are constructed. More specifically, this research uses visual inputs to analyse how higher education students represent and evaluate responses to climate change.

\section{METHOD}

In order to answer the above mentioned research questions, eight focus groups were conducted with undergraduate students belonging to universities based in the four countries that are part of this project: Universidade Federal do Paraná (Brazil), Universidad Nacional Autónoma de Coahuila (México), Universidade do Minho (Portugal) and Universidade de Santiago de Compostela (Spain). Students were invited to participate in the study via in-class announcements made by the researchers, who also act as teaching staff at those universities. Announcements were also placed in advertising boards as well as on student mailing lists. 
The intentional sample for this research was composed by a total of 50 students, 19 female and 31 male, by using the field of studies as the criterion for selection: in each country, a focus group was conducted in the academic field of Sciences and Engineering (S\&E) and another one in the Social Sciences and Humanities (SS\&H). Focus groups ranged from 5 to 8 participants, a size that is considered acceptable in the literature (Morgan, 1993; Gutierrez Brito, 2008), and they were held at the universities' facilities. Prior to the start of the discussion, participants were informed about the topic of the study, the methodology of the discussion group, and reassured that their identities were confidential. Finally, they were asked to consent to audio recording.

Table 1. Sample size and composition

\begin{tabular}{|c|c|c|c|l|}
\hline Country & Focus Group & Women & Men & \multicolumn{1}{|c|}{ Scientific field } \\
\hline \multirow{2}{*}{ Brazil } & 1 & 2 & 3 & Sciences and Engineering \\
\cline { 2 - 5 } & 2 & 3 & 2 & Social Sciences and Humanities \\
\hline \multirow{2}{*}{ Mexico } & 3 & 0 & 5 & Sciences and Engineering \\
\cline { 2 - 6 } & 4 & 2 & 4 & Social Sciences and Humanities \\
\hline \multirow{2}{*}{ Portugal } & 5 & 4 & 4 & Sciences and Engineering \\
\cline { 2 - 6 } & 6 & 3 & 5 & Social Sciences and Humanities \\
\hline \multirow{2}{*}{ Spain } & 7 & 3 & 3 & Sciences and Engineering \\
\cline { 2 - 5 } & 8 & 2 & 5 & Social Sciences and Humanities \\
\hline \multirow{4}{*}{ Source: Authors' data }
\end{tabular}

The group discussions were organized into diverse topics, ranging from awareness of the causes of climate change, processes involved in climate change, its consequences and potential responses. All themes were approached with an innovative technique, consisting on the presentation of 16 consecutive images previously selected by the research team, which acted as initial stimuli for an open conversation among the participants. The images were the same for all eight groups, and were presented together with an open question: Which relation do you see between this image and climate change?

The application of the same "stimuli-images" in all focus groups aimed to elicit and compare, under a similar and, to some extent, natural context for all participants, the repertoire of existing representations about climate change, as all participants were invited to discuss the same topics, connecting their arguments to their own local reality and to their own scientific and cultural representations.

In order to select the images to stimulate group interactions around climate change, a three-stage process was completed. First, an online search was conducted with the most common Internet search engines and the images dealing with climate change topics with a higher position and visualization were identified. Secondly, those images were presented to 29 students of the undergraduate programme in Social Education at the Universidade de Santiago de Compostela followed by the question "which images do you relate to climate change?" This led to a selection of 27 images relevant to this project. Thirdly, the research team selected 16 out of these 27 images in order to adapt the amount of visual inputs to the standard duration of a focus group, around 90 minutes long. Additionally, both the images and the technical procedure were validated by a group of students in the School of Education Sciences at the Universidade de Santiago 
de Compostela. Once this design phase was completed, the research instrument was applied in all the groups conducted in the four countries.

The 16 images aimed at stimulating participants to explore the following issues: a) processes linked to climate change, which were portrayed by means of two images showing a hand protecting the Earth from the Sun and a recreation of the greenhouse effect by means of a recipient of daily use; b) causes of climate change, which were represented by a photograph of an urban landscape with a high density of population, the inside space of a shopping mall, an airport terminal with several airplanes, a green field in the mountains with cows, and a landscape deforested by human action; c) consequences of climate change, which were evoked by five pictures: an iconic image of Planet Earth burning in flames, a landscape with Antarctic fauna, a photo of the tsunami caused by the Fukushima earthquake in 2011 (a natural phenomenon that popular culture tends to relate with climate change), a scene depicting two African women collecting water from a natural source that is nearly dried out, and a cartoon representing a desert landscape where one can see, face to face, a man experiencing hunger and a polar bear; d) responses to climate change, which were represented by an advertisement to a car with a clear reference to its low $\mathrm{CO}_{2}$ emissions, an urban agricultural plot of land, a demonstration of an environmental organization in front of a public institution, and the presidential table of the 18th Conference of Parties to the UNFCCC, held in Doha (Qatar) in 2012. These two last images were also used to illustrate the local and/or global representation of climate change and its political dimension.

The transcript of each discussion group maintained the original language (Portuguese, Spanish or Galician). The analysis was carried out with version 6 of Atlas.ti and common theme categories were created in Spanish. The four topics selected to run the focus groups discussions were employed as analytical meta-categories, anchoring new and more specific categories that link responses to climate change with technological, political, social and educational initiatives. We also differentiated segments framed in terms of mitigation from those linked to adaptation to climate change. Reflecting the discursive positionings and interactions in the focus groups, we also created a category on "barriers" that hamper the implementation of responses to climate change. In order to embrace the complexity of this research topic, we distinguished students' discourses according to the area of study - Sciences and Engineering, and Social Sciences and Humanities - and to country.

\section{RESULTS}

This section presents our main findings based on the thematic analysis of focus group discussions focusing on responses to climate change. Most of the students' arguments pointed to mitigation practices whereas the amount of proposals related to adaptation was remarkably lower. A large fraction of the discussion focused on barriers that make responses to climate change difficult to launch and develop.

Direct mentions of responses to climate change were closely linked to the four images selected to illustrate this topic. Pictures depicting the advertisement of the car and the environmental protest demonstration, together with the urban area devoted to agriculture and the Conference of Parties, fostered debate and the emergence of 
different perspectives. However, other images that were not directly linked to responses, such as the man-bear cartoon and the photograph of a big city stimulated a significant amount of utterances that can be labelled as responses. The remaining images either led to a smaller number of mentions to responses or were only mentioned as anecdotes.

\subsection{MITIGATION}

Table 2 synthetizes the main dimensions and options to mitigate the emission of greenhouse gases identified in each of the eight groups.

Table 2. References to proposals for climate change mitigation in focus groups

\begin{tabular}{|c|c|c|c|c|c|c|c|c|c|}
\hline & \multicolumn{2}{|c|}{ Brazil } & \multicolumn{2}{|c|}{ Mexico } & \multicolumn{2}{|c|}{ Portugal } & \multicolumn{2}{|c|}{ Spain } \\
\hline & & 1 & 2 & 3 & 4 & 5 & 6 & 7 & 8 \\
\hline \multirow{3}{*}{ Individual } & Awareness & $\mathrm{X}$ & $\mathrm{X}$ & $\mathrm{X}$ & $\mathrm{X}$ & $\mathrm{X}$ & $\mathrm{X}$ & $\mathrm{X}$ & $\mathrm{X}$ \\
\hline & Responsibility & $\mathrm{X}$ & & & & & & $\mathrm{X}$ & \\
\hline & Recycling & & & & & & & $\mathrm{X}$ & \\
\hline $\begin{array}{l}\text { Education and } \\
\text { knowledge }\end{array}$ & $\begin{array}{l}\text { Foster education, knowledge } \\
\text { and change of mentality }\end{array}$ & & & & $\mathrm{X}$ & $\mathrm{X}$ & $\mathrm{X}$ & & $\mathrm{X}$ \\
\hline \multirow{2}{*}{ Social action } & Social protest & $\mathrm{X}$ & & & $\mathrm{X}$ & $\mathrm{X}$ & & & $\mathrm{X}$ \\
\hline & Engagement and citizen organization & & & & & $\mathrm{X}$ & & & $\mathrm{X}$ \\
\hline \multirow{3}{*}{ Public policies } & $\begin{array}{l}\text { Development of government policies } \\
\text { and environmental regulations }\end{array}$ & $X$ & $\mathrm{X}$ & & & $\mathrm{X}$ & $X$ & & \\
\hline & Reforestation & & & & & & $\mathrm{X}$ & & \\
\hline & $\begin{array}{l}\text { Stimulate use of alternative means of } \\
\text { transport }\end{array}$ & & $\mathrm{X}$ & & & & & & \\
\hline \multirow{4}{*}{$\begin{array}{l}\text { Economics and } \\
\text { resource- } \\
\text { related }\end{array}$} & Change food model & & & & & $\mathrm{X}$ & $\mathrm{X}$ & & $\mathrm{X}$ \\
\hline & Responsible consumption & & & & & & $\mathrm{X}$ & $\mathrm{X}$ & $\mathrm{X}$ \\
\hline & Modify the economic system & & & & & & $\mathrm{X}$ & & $\mathrm{X}$ \\
\hline & Reduce the ecological impact of products & & & $\mathrm{X}$ & $\mathrm{X}$ & & & $\mathrm{X}$ & \\
\hline Technological & Technological change & $\mathrm{X}$ & & $\mathrm{X}$ & & $\mathrm{X}$ & $\mathrm{X}$ & & $\mathrm{X}$ \\
\hline
\end{tabular}

\subsubsection{Individual responses}

Individual-level responses were mentioned in all groups, although they were mostly posited in terms of awareness of climate change and of one's contribution to greenhouse gas emissions. Responses to climate change can only become solid and sustainable proposals to the extent that human beings, on a personal level, understand their impact on ecosystems. Participants in several groups pointed out that being aware of and developing a sense of individual responsibility towards climate change implies avoiding to produce damages arising from the sphere of personal action.

Unfortunately when things start to change and we begin to see the consequences of our acts is when we begin to become aware. (Gr. 3, Mexico, S\&E)

This awareness is very important for creating a good person, a good person that cares about their environment, not only their situation as a human being, but also the ecological situation and also on a large scale. (Gr. 8, Spain, SS\&H) 
The groups of Brazil and Spain emphasized individual responsibility as an important factor, expressed as taking care of the planet and being committed to the wellbeing of future generations. Being aware of and taking responsibilities in relation to climate change should translate into personal behaviour and in overcoming what was viewed as the general mentality of an alienated and consumerist society.

(...) responsibility doesn't only belong to a group, but individual responsibility has great value in these issues. (Gr. 1, Brazil, S\&E)

However, participants hardly ever referred to specific individual responses (mentions to recycling in one of the Spanish groups were an exception).

\subsubsection{Social action responses}

For the students in our study, awareness should not be limited to the personal sphere. Widespread engagement of citizens is important and it must be organized so as to generate significant responses to climate change. This was exemplified in practice when, for example, Spanish students referred to responsible consumption groups.

We have to be aware that there are groups concerned with responsible consumption. We have meetings many times and there are groups for responsible consumption, you know, we do what we can... (Gr. 8, Spain, SS\&H)

Participants in the Social Sciences and Humanities group in Spain argued that citizens have the responsibility to get organized and carry out concrete actions, such as social protest, which is channelled in various ways and was viewed as a relevant means to achieve ecological and social objectives, as well as an instrument to inform and make society aware of problems such as climate change.

Of course, the more noise that is caused by speaking straightforwardly, the better. And, I say, that one of the best ways to raise awareness is en masse, to draw attention directly to the context. (Gr. 8, Spain, SS\&H)

I do not think I have to choose a form of struggle. There are a lot of open fronts, they are not exclusive: if you can be in the streets, you have energy, and your vital moment allows you to, I really encourage you (...) you have to poke people and inform them, if you are in the streets you are informing people. (Gr. 8, Spain, SS\&H)

\subsubsection{Education and knowledge-related responses}

A positive vision of education was put forth as a means to understand situations such as social, economic and environmental crisis, and to stimulate people to act accordingly. According to focus group participants, the mitigation of global warming requires "good human beings" (Gr. 8, Spain, SS\&H), having awareness and knowledge about what is happening in their environment and the problems posed by climate change. To educate means to form people respectful of all forms of life and able to live in harmony with the environment.

Creating good people (...) people that are curious, open, intelligent, willing to discover new things, to be in harmony with what surrounds them. (Gr. 8, Spain, SS\&H) 
Following this perspective, members of Portuguese focus groups considered that education implies a change of mentality, transforming people and societies.

Because I think the problem is not just politics, it also has to do with each one's mentality. If others do not do, why do I do it? But if I did, then the neighbour would see, and also do, and if we can get a great mass of people at least trying to reduce emissions... (Gr. 5, Portugal, S\&E)

I'm thinking a little about environmental education because I think it's important. (Gr. 6, Portugal, SS\&H)

\subsubsection{Public policies responses}

Responses to climate change can be developed via public policies and environmental legislation. Students emphasized mandatory and enforced regulations, as well as sanctions for individuals and institutions generating uncontrolled emissions.

But more than anything, the government, the one leading this, must demand that intentions do not remain as intentions, but that the existing plans and projects are executed. (Gr. 4, Mexico, SS\&H)

I think it does not make sense to impose rules without sanctions. (Gr. 6, Portugal, SS\&H)

In addition to running things at the local and national levels, focus groups participants considered that governments must also invest on responses at the global scale. Students maintained that they should be concerned with generating a global consensus in order to align multiple interests, for example, to develop less polluting products, to promote responsible consumption or to reforest degraded environments.

(...) it works like this: if Saudi Arabia has oil, they'll want to rely on fossil fuels, if Finland has wind power, they'll want to rely on renewables... Then everyone pulls things to their side. The point is to reach a consensus. (Gr. 5, Portugal, S\&E)

I think it has to do with the power to make important decisions in order to promote changes. I think it is only (governments) who could get things moving on a large scale. (Gr. 5, Portugal, S\&E)

Students from Brazil considered that public policies should also serve to promote and support local initiatives, for example, the development of transport systems with lower levels of greenhouse gas emissions.

And in this issue of carbon emissions, small-scale policies are very welcome. For example, closing the Paulista (avenue) is a policy that should always happen, imagine here, for example, closing Marechal (avenue) a whole weekend, right, a period when you pull cars out of the street and everything else contributes a little bit. (Gr. 2, Brazil, SS\&H)

- Are you thinking ecologically? So why not invest in bikes, right, why a car?

- Bikes depend on good cycle paths.

- Exactly! And good cycle paths depend on the state and on investment... (Gr. 2, Brazil, $\mathrm{SS} \& \mathrm{H})$ 


\subsubsection{Economics and resource-related responses}

Spanish and Portuguese SS\&H students considered that the main cause for the generation of greenhouse gases is the capitalist economic model, which is based on irrational and unlimited consumption. Consequently, responses must be geared towards the transformation of the economic system.

The big cause of climate change and pollution is the economy. For a true change, a significant one, we must modify our economic system, our production system. (Gr. 8, Spain, SS\&H)

Regarding economics, very often we only think about production, production, production, and we forget the rest. And so this is the concern we must have: the economy in correlation with the environment and society itself. (Gr. 6, Portugal, SS\&H)

A rational use of resources must be the basis for transforming the economic model. For example, it is necessary to reduce the ecological impact of products in the manufacture of ecological cars.

From my point of view, more than (producing) an ecological car, they should innovate the manufacturing process, making it ecological (...) I say that more than the car, they should change a part of the process, it can be a tire, a light, a pin, a seat, there I would use the ecology. (Gr. 3, Mexico, S\&E)

Associated to this is the development of responsible consumption behaviors, exemplified by the change in the food model based on meat consumption.

We have an alternative as well and I do not mean sacrificing animals like this in an unconscious way, but addressing a change in our food. We do not need as much meat as industries want to sell us. (Gr. 8, Spain, SS\&H)

A SS\&H student in Spain proposed a boycott to consumption, as a real measure of protest against the harmful effect of the production system on the environment and people's lives.

To change the situation there is not only this option (demonstrations), there are other and much more effective ones, such as to stop consuming a product. These are forms of protest that can be terribly effective in the end. (Gr. 8, Spain, SS\&H)

\subsubsection{Technological responses}

Focus groups participants appear to believe that technology plays an important role in climate change mitigation. Students in Brazil, Spain and Portugal displayed an optimistic view of technology and its potential to reduce the impact of $\mathrm{CO}_{2}$ emissions.

A time may arrive when we can avoid that (climate change) with better technology. (Gr. 8, Spain, SS\&H)

I am optimistic and I believe that a change of mentality can lead to new technologies reversing this situation (sea level rise, melting of the poles, warming of the atmosphere). (Gr. 8, Spain, SS\&H) 
The ecological car as a means to reduce $\mathrm{CO}_{2}$ emissions and mitigate the threat of climate change is a paradigmatic example. A significant number of students in Brazil, Spain and Portugal agreed that this is one of the most hopeful and realistic options to improve environmental quality and correct past errors.

I find this type of initiative (ecological car) very interesting to try, in any way, to minimize the human impact of global warming, pollution and everything, I think it's very cool. (Gr. 1, Brazil, S\&E)

Hope in technology was not limited to the transformation of the transport system; it also took the shape of other options, such as the development of new instruments for the production of renewable energy.

\subsection{ADAPTATION}

Mentions of response actions for adaptation to climate change were limited. They were found among S\&E students from Brazil and Portugal, and among SS\&H students from Spain (Table 3). Another aspect that is worth mentioning is that they were linked to discourses on the consequences of climate change, such as the images of the Antarctic landscape and the cartoon. The context in which adaptive actions are developed was characterized, according to different focus groups, by alteration or disappearance of ecosystems and species, change in water patterns, decline in agricultural productivity, loss of coastal areas and environmental pollution. SS\&H groups of Mexico, Spain and Portugal, and the S\&E Portuguese group, even described an apocalyptic future and a lifeless planet.

Table 3. Proposals for climate change adaptation in focus groups

\begin{tabular}{|l|c|c|c|c|c|c|c|c|}
\hline & Brazil & \multicolumn{2}{|c|}{ Mexico } & \multicolumn{2}{c|}{ Portugal } & \multicolumn{2}{c|}{ Spain } \\
\cline { 2 - 10 } & $\mathbf{1}$ & $\mathbf{2}$ & $\mathbf{3}$ & $\mathbf{4}$ & $\mathbf{5}$ & $\mathbf{6}$ & $\mathbf{7}$ & $\mathbf{8}$ \\
\hline Technological change & & & & & $\mathrm{X}$ & & & \\
\hline Containment barriers & $\mathrm{X}$ & & & & & & & $\mathrm{X}$ \\
\hline Adaptation of species & & & & & $\mathrm{X}$ & & & \\
\hline Migration of species & & & & & & & $\mathrm{X}$ \\
\hline
\end{tabular}

\subsubsection{Technological change}

As in relation to mitigation, technology emerged as a pivotal element in students' analysis of possibilities for adaptation. Technological progress was considered an indicator of the human capacity to develop knowledge aimed at overcoming the challenges of the environment. In this sense, the function of technology is to adapt human life to the changing conditions of the environment caused by climate change.

(...) there is a lot of technology being developed and there will always be methods to make us able to adapt. (Gr. 5, Portugal, S\&E)

Yes, not so much to reverse the situation, but to adapt to what is happening, to what is appearing, and to have that capacity, yes... (Gr. 5, Portugal, S\&E) 


\subsubsection{Containment barriers}

The S\&E group in Brazil referred to the construction of containment barriers in the face of flood risks and sea level rise:

This reminded me of the time I went to Ceará. There were several houses built in front of the sea and the water was already splashing on the stones that they were placing to protect the houses, it was already two years ago, so I believe that in a few years, these houses will be gone... If they built the houses there, it's because the sea was far away. I think this also has to do with rising sea levels. (Gr. 1, Brazil, S\&E)

I agree with them, several beaches here in Paraná and Santa Catarina have already built those walls to block the sea, for the sea not to get to the city. (Gr. 1, Brazil, S\&E)

Spanish students also referred to the impacts of sea level rise and to how this issue is being faced in specific places such as Venice:

It is (necessary) to build locks to save Venice because the way the water level is rising it will be flooded and the problem they have with "the high water" is horrible because it is growing... in a few years Venice will be completely flooded. There is a project at national level to solve it, but it is a local project in a specific site and in the rest of Europe... (Gr. 8, Spain, SS\&H)

\subsubsection{Adaptation and migration of species}

The term "adaptation" was used in relation to both humans and animal species:

It's normal. The coldest fish species are accustomed to cold and will disappear with global warming. Maybe some species will be able to adapt, but others will probably disappear. (Gr. 5, Portugal, S\&E)

The Spanish and Portuguese SS\&H groups mentioned migratory processes as an adaptive strategy for animal species:

If there is an increase of one degree... baah ... that's nothing! And maybe for half a degree there is a species that has to move away from an area where it can no longer survive. (Gr. 8, Spain, SS\&H)

\subsection{BARRIERS}

In the discourse of students from Brazil, Spain and Portugal -Mexico being an exception- arguments were often focused on the barriers that hinder or impede the adoption of mitigation and adaptation responses. Table 4 summarizes these barriers. 
Table 4. Barriers mentioned in focus groups

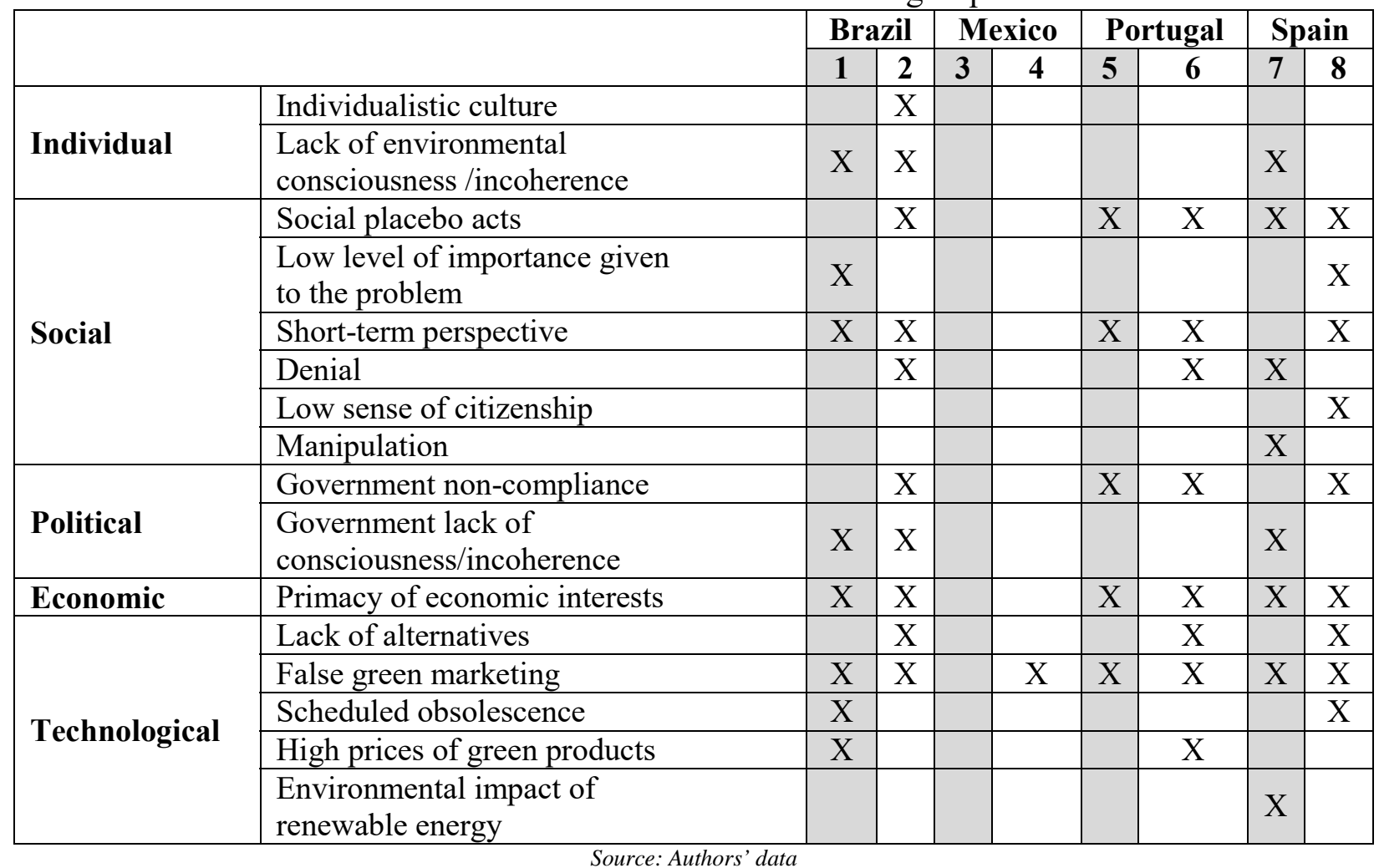

The general discursive position of the students is one of resigned acceptance of reality as something that is difficult to transform. On the one hand, they are aware of possible mitigation responses. On the other hand, they consider that these responses are conditioned by economic, social, cultural, technological, behavioural and ethical factors.

\subsubsection{Personal barriers}

For Brazilian students, the modern individualistic culture inhibits effective responses to climate change. Many refer to the abandonment of a communitarian worldview in current societies, where personal/individual wellbeing has prevalence. Consequences of one's acts for nature or for other people are not taken into consideration.

All the issues that concern a group, that are collective, are set aside. That's a politics that is gradually constructed, and sustainability and ecological issues are not exempt from that. It's about individualism growing. Climate change, discussions on climate change, engagement, etc., all fall into that. (Gr. 2, Brazil, SS\&H)

In the students' discourse, this is aggravated by a lack of environmental consciousness or incoherence, as most individuals display forms of behaviour in their daily lives that do not suggest any commitment to climate change mitigation nor to the quality of life of future generations. Hence, discourses are not validated by behaviours.

These people say "I am not going to be here when we run out of oxygen, so yes, I'll push down the pedal of my Ferrari". (Gr. 7, Spain, S\&E)

It is not just climate change that people here do not protest against. The same is true for demonstrations in general, for instance against war in Syria. So I just go home, have my dinner and sleep. (Gr. 8, Spain, SS\&H) 
- Sometimes people forget.

- They don't forget, they pretend they forget. They settle for the status quo. (Gr. 5, Portugal, S\&E)

In students' opinion, people end up settling for a certain reality. In the words of students from Brazil, Spain and Portugal, environmental concerns linked to climate change are relegated because of personal comfort and ambition. The need to transform reality is acknowledged but personal costs or the chances of having reduced "privileges" are not accepted.

Portuguese students say that citizens perceive climate change as something that takes place far away and in an unforeseeable future, hence something that is distant from their reality. This view leads to inaction and to behaviours that are at odds with the challenge of climate change.

The thing is that if it is in Africa, it is far away from us, then we are indifferent. Climate change will only be a problem when it arrives at our home (Gr. 5, Portugal, S\&E)

- In which time scale do you think climate change will become really serious?

- Centuries. (Gr. 5, Portugal, S\&E)

\subsubsection{Social barriers}

Environmental issues do not occupy a relevant place among social concerns. In students' opinion, People have other priorities, which relegate climate change to a secondary level. This type of barrier - of individual and social nature - leads, for example, to a lack of mobilization.

I think this is an initiative that is missing here in Brazil. I have never seen a demonstration against pollution in São Paulo. (Gr. 1, Brazil, S\&E)

The only thing that matters to you is the (football) match, if most people care more about the match on Friday and about going out, these things (climate change) in general do not matter to anyone. (Gr. 8, Spain, SS\&H)

I sometimes talk to my friends about this issue (climate change) and their answer is always that there are more important things. (Gr. 8, Spain, SS\&H)

Distrust in social responses to climate change is aggravated, in the words of a S\&E student in Spain, when actions, such as social protest, respond to a principle of manipulation. This pessimistic view also applies to other areas, such as cultivation in family gardens, which according to university students in Brazil, Portugal and Spain only have a "placebo effect", aimed at appeasing citizens' conscience but without any real significance for the mitigation of climate change.

Most people, unfortunately, are manipulated. With good intentions, but manipulated anyhow. (Gr. 7, Spain, S\&E)

I think this (urban gardens) does not have much environmental impact. It's a way to spend it time, to have fun and to have quality products to consume. (Gr. 5, Portugal, S\&E) 
"Look, we do something, see? It's working... you know?" It's placebo in quotes, deceitfulness. (Gr. 7, Spain, S\&E)

Generally speaking, among students, there is little hope in the possibility of influencing and transforming citizenship. Lack of access to qualified information that could contribute to understand climate change is an aggravating factor. In this context, despite isolated actions and the sum of the individual responses, problems linked to climate change will not be solved.

We live in such precariousness that lack of information affects all sectors, not just the climate (Gr. 2, Brazil, SS\&H)

But what can you do against that really, as a citizen, you can get involved in an NGO, hmm or get into any kind of movement or so, basically that's what people will continue to do. (Gr. 8, Spain, SS\&H)

\subsubsection{Economic barriers}

Nearly all students defined the economic system as the great barrier to change, especially given that the interests of individuals, institutions and countries for the most part are determined by economics. As long as the economic system does not change, little or nothing will change.

It's hard to know to what extent each country really acts willingly or has an interest in implementing good practices towards a healthier environment, right, since this will always be going against the tide, always against economic issues. It's economics that ignite everything else. (Gr. 2, Brazil, SS\&H)

Sustainable yes, but not harmful to my pocket, right? (Gr. 2, Brazil, SS\&H)

Also if we stop using fuels a gigantic global market will break... (Gr. 1, Brazil, S\&E)

The economic model truncates, limits and hampers the implementation of responses to climate change, as it responds to business interests that, for the most part, do not seek to reduce greenhouse gas emissions. SS\&H students from Spain see an example of this situation in the renewable energy policy adopted in the country.

Spain was a leading country in terms of renewable energy (...) now if you want to produce energy on your own you have to pay, that is, it is ridiculous. (Gr. 8, Spain, $\mathrm{SS} \& \mathrm{H})$

Economics is what moves current thinking, so if something does not make a profit it's not good. So let's invest in sustainable policies, okay, but the market has to return a profit. (Gr. 2, Brazil, SS\&H)

Market economics generates forms of pressure that end up crippling initiatives of mitigation of climate change, inasmuch as they may tamper with a central element in people's life, employment.

Of course, you can close the industry that throws out detritus or that shoots up gases, but that has a counterproductive effect as all those workers will lose their jobs, then what to do... (Gr. 8, Spain, SS\&H) 


\subsubsection{Political barriers}

The responsibility of national governments in relation to climate change was mentioned in the group discussions in Brazil, Portugal and occasionally Mexico. Brazilian students started by highlighting the lack of willingness of governments to get involved in concrete and effective actions.

Governments' will is missing. Sometimes putting things down on paper is easy, isn't it, but going for it and really doing it is difficult. (Gr. 1, Brazil, S\&E)

Governments, like people, set themselves objectives and goals in relation to climate change but fail to meet them. Students argue that they appear committed but are inconsistent in terms of action. An example is the signing of intergovernmental treaties to limit emissions of greenhouse gases, which are not fulfilled, slowing down progress in the fight against climate change.

All the countries sign the document but to what extent do they comply? It's a political treaty, a public treaty and yet countries do not comply. (Gr. 6, Portugal, SS\&H)

Many goals, but the effect is still not what you expect, right, because goals leave much to be desired, right, they are not fulfilled. Many goals and few practices (Gr. 2, Brazil, SS\&H)

\subsubsection{Technological barriers}

Technology was highlighted as a relevant factor in the mitigation and adaptation to climate change. However, its development and application are not exempt from controversy. In this study, that was especially the case of transport-related technology, where we found an ambiguous, even negative view of proposals for environmentally friendly technologies. Students (in all groups except S\&E students from Mexico) maintained that plans for ecological cars respond to economic interests and not to the intention to fight climate change. They considered that sustainable technology is fashionable, a fact that is used to promote such goods, but without the commitment or concern to generate real change. Mercantilism and corporate interests give rise to false eco marketing, which disparages and harms pro-environmental technology initiatives.

That's a car that pollutes less but that pollutes still. But if you show it in green colour and put in a leaf that does it. The point is that the image you convey is that you are totally engaged with global change, with climate change. (Gr. 8, Spain, SS\&H)

I think it's kind of fashionable to say it's sustainable, I think it's more about selling than about concern. (Gr. 1, Brazil, S\&E)

It's a means of marketing targeting those who are worried about polluting less. That's why they created this eco thing, to find a way of selling cars to people who care more about the environment. (Gr. 6, Portugal, SS\&H)

Technological products were also questioned because they are part of a polluting and predatory economic logic. Industry supports consumerism through the intentional design of products whose durability is limited and through scheduled obsolescence. 
Things are no longer made to last, for example, you see a cell phone, you buy it and in one year it is already horrible, it stops working, falls to the ground and breaks, everything is too expensive to fix (...) what are you going to do about that? You'll throw it away. Often it is the same thing with computers. (Gr. 1, Brazil, S\&E)

The price of green products is also a factor limiting their integration into everyday life. For example, hybrid or electric cars are expensive and consequently inaccessible to the majority of the population.

Whatever is greener or natural is more expensive and hence people end up not going for the most expensive obviously. (Gr. 1, Brazil, S\&E)

An added difficulty concerns the development of viable alternatives for certain forms of transport, such as air transport. Airplanes were considered unavoidable sources of pollution.

Right now this is the only option to make a transoceanic trip. Nor do we think much about developing other, more sustainable solutions. (Gr. 6, Portugal, SS\&H)

I personally am not that dramatic in that regard and I believe that the use of airplanes is necessary. (Gr. 4, Spain, SS\&H)

\subsection{Differences between the groups}

The main aspect that should be pointed out concerns the richness of arguments, which was higher among SS\&H students, especially in Spain and Portugal. The discourse of S\&E students was less elaborate and did not stand out in terms of scientific backing. The two groups in Brazil were more similar in relation to the range of arguments used, whereas in the case of Mexico, the groups had a less developed argument base than in other countries and also showed less interest in responses to climate change.

Regarding the spatial axis, local identity introduces nuances influenced by realities or experiences of the near environment, an aspect that adds depth and diversity to the argumentation. Spanish students referring to renewable energies, their environmental impact and the way public policies have slowed down their development is a good example. Among Brazilian students, examples of coastal mitigation actions stood out. In Portugal, regulatory shortages were reported in comparison with other countries. It is possible to identify a European view on consumption as both Portuguese and Spanish students refer to food practices, to responsible consumption and even to a new economic model as responses to climate change (in the case of the Spanish groups, there is an explicit reference to participation in activist groups focusing on consumption). Connections can be drawn with the contexts and the discourses that circulate in the two European countries.

In spite of local singularities, this research identified a "global" consensus discourse that is common to most groups. Students from the four countries share views about climate change that suggest a poor scientific understanding of the problem; criticism of the economic system; a call for solutions of economic, technological, and political nature; and for the transformation of social and personal lifestyles. 
The discourses of students from Spain, Brazil and Portugal focused mostly on barriers that hamper the development and implementation of responses to climate change (the Mexican groups were an exception in this respect).

Groups in Brazil, Spain and Portugal argued that a short-term vision blocks solutions to the problem, and that the limited importance given to climate change also acts as a brake. Above all, students prioritize the need for citizen engagement with the issue, highlighting a lack of concern and of sense of urgency on the part of the public, which has also been identified in research.

\section{DISCUSSION AND CONCLUSIONS}

This research shows that university students are aware of possible responses to climate change. Students' discourses were organized around ideas that contemplate possibilities of change, actions of mitigation, and barriers or difficulties that limit responses. References to adaptation were sparse, despite the growing need for plans in this area (Jacobi and Maia, 2016). Nonetheless, students showed a considerable capacity for critical reflection on the challenges of climate change. The arguments presented point to the relevance of several discursive axes, as found in other studies (López-Pastor, 2010): present and future, local and global, personal and systemic.

The majority of the participants put a significant emphasis on technological advances. However, despite generating some optimism, hope in those advances was nuanced by distrust towards the system of production and the current model of consumption. In this sense, strong criticism of "green" products was striking, as our example in the field of transport suggested. Multiple students talked about the "ecological" as part of a deceptive marketing strategy, of "false marketing". Students as a whole expressed a negative view of the economic system, which they identified as the objective cause of climate change. This perception leads to the need to transform the production system, through the modification of consumption habits and the development of a sense of responsibility among individuals, societies and governments.

Some concrete responses to climate change were mentioned only in a single group and were not the object of debate or dissent: reforestation, promotion of public transport and recycling. Mentioned only anecdotally, recycling contrasted with its prevalence in the discourses of the Spanish population on climate change (Meira et al., 2013), as well as of Spanish university student groups (Meira and Arto, 2014), found in earlier studies.

In terms of personal action, students emphasized issues related to awareness, education and information, as well as engagement with citizen organizations, the development of forms of social pressure, change in consumption models and the exercise of political power as effective tools for climate change mitigation. However, some of these possibilities conflict with the distrust expressed towards "small" individual responses to mitigate climate change, for example, urban gardens, which were described as "placebo acts" whose sole function is to appease the individual conscience. Likewise, among SS\&H students in Spain, we identified a position of defense of social protest, but also recognition of its low incidence. 
Overall, the tension between possibilities and barriers, some of which are perceived as unsurmountable, results in a weakly optimistic vision and a mostly conformist and resigned stance on the part of the participants in this study. According to López-Pastor (2010), the ambivalence observed in debates on climate change cuts across different topics and discourses. Instead of being interpreted as incoherence, this is one of the characteristic features of Bauman's liquid modernity (2000).

Despite some variation in the arguments that were put forth, we found scarce differences between the groups of students in the two broad fields of study that we looked at. In most cases, their discourse appears to be based on knowledge and information received either through the media, direct experience of local realities, and only to a smaller extent through the educational systems, as found by Morgado et al. (2017). Although some of the topics mentioned by students are associated with scientific culture, explanations built upon popular culture were predominant, resulting in a representation of climate change that is broadly homogeneous for all participants. A comparison between countries, and especially between the discourses of European and Latin American students, points to a greater diversity, as they often referred to national realities. In the Mexican case, critical analysis was less marked than in the other countries.

Given the limited number of participants involved in this study, more research is needed to continue examining social representations of climate change among university students. More than offering definitive results, this study has aimed to explore novel research possibilities. The joint analysis of national/cultural differences and of academic cultures is innovative and can offer useful contributions to understand the dynamic construction of social representations. Similarly, the use of images in focus groups is a valuable methodological option to deepen the analysis of iconic aspects in social representations, thus adding to a domain of research that is still under-explored. 


\section{REFERENCES}

Bauman, Zygmunt (2000). Liquid Modernity. Cambridge: Polity Press.

Cabecinhas, Rosa, Alexandra Lázaro and Anabela Carvalho. 2006. "Lay representations on climate change", Proceedings of the 25 th Conference of the International Association for Media and Communication Research, 504-508. s/1: IAMCR. URL: http://hdl.handle.net/1822/5335

Capstick, Stuart, Lorraine Whitmarsh, Wouter Poortinga, Nick Pidgeon, and Paul Upham. 2015. "International trends in public perceptions of climate change over the past quarter century". Climate Change 6 (4): 35-61. http://dx.doi.org/10.1002/wcc.321

Corner, Adam, et al. 2015. "How do young people engage with climate change? The role of knowledge, values, message framing, and trusted communicators." Wiley Interdisciplinary Reviews: Climate Change 6.5: 523-534.

Correa López, María I. 2012. "Cambio climático y representaciones sociales entre estudiantes de educación superior”. In La percepción social del cambio climático, edited by Benjamín Ortiz Espejel and Concepción Velasco Samperio, 107-122. Puebla: Universidad Iberoamericana Puebla.

Fischer, Anke, Vera Peters, Mirjam Neebe, Jan Vávra, Antoinette Kriel, Miloslav Lapka, and Boldizsár Megyesi. 2012. "Climate change? No, wise resource use is the issue: Social representations of energy, climate change and the future". Environmental Policy and Governance 22 (3): 161-176. http://dx.doi.org/10.1002/eet.1585

González-Gaudiano, Edgar and Lucía Maldonado-González. 2013. Los jóvenes universitarios y el cambio climático. Un estudio de representaciones sociales. Xalapa: Universidad Veracruzana.

Gutiérrez Brito, J. 2008. Dinámica del grupo de discusión. Madrid: Centro de Investigaciones Sociológicas, Cuadernos Metodológicos.

IPCC. 2014. Climate Change 2014: Synthesis Report. Contribution of Working Groups I, II and III to the Fifth Assessment Report of the Intergovernmental Panel on Climate Change [Core Writing Team, R.K. Pachauri and L.A. Meyer (eds.)]. Geneva: IPCC.

Jacobi, Pedro, and Roberta A. Maia. 2016. "Desafíos y estrategias para fortalecer las relaciones entre ciencia y política en relación al cambio climático". Ambiente \& Sociedade XIX (4): 195-210.

Leiserowitz, Anthony. A. 2006. "Climate change risk perception and policy preferences: the role of affect, imagery, and values". Climatic Change 77(1-2): 45-72.

López-Pastor, Ana. T. 2010. "Algunas reflexiones sobre las representaciones sociales en torno al cambio climático. Sugerencias de cara a la comunicación". In Eduación ambiental y cambio climático. Respuestas desde la comunicación, educación y participación pública, edited by Francisco Heras et al., 43-76. A Coruña: CEIDA. 
Lorenzoni, Irene, Sophie Nicholson-Cole, and Lorraine Whitmarsh. 2007. "Barriers perceived to engaging with climate change among the UK public and their policy implications". Global Environmental Change 17: 445-459.

Meira, Pablo. Á., Mónica Arto, Francisco Heras, Lucía Iglesias, Juan J. Lorenzo, and Pablo Motero. 2013. La respuesta de la sociedad española ante el cambio climático. 2013. Madrid: Fundación Mapfre.

Meira, Pablo Á., and Mónica Arto. 2014. "Representação das mudanças climáticas em estudantes universitários na Espanha: contribuições à educação e comunicação". Educar em Revista 3, 15-33.

Moloney, Gail, Zoe Leviston, Timothy Lynam, Jennifer Price, Samantha StoneJovicich, and Dunclan Bla. 2014. "Using social representations theory to make sense of climate change: what scientists and nonscientists in Australia think". Ecology and Society 19(3): 19. DOI: 10.5751/ES-06592-190319

Morgado, F., Bacelar-Nicolau, P., Rendon von Osten, J., Santos, P., Bacelar-Nicolau, L., Farooq, H., ... \& Azeiteiro, U. 2017. Assessing university student perceptions and comprehension of climate change (Portugal, Mexico and Mozambique). International Journal of Climate Change Strategies and Management, 9(3).

Morgan, D.L. (Ed.). 1993. Successful focus groups. Advancing the state of the art. Newbury Park: Sage.

Moser, Susanne, and Lisa Dilling. (Eds.) 2007. Creating a Climate for Change. Cambridge: Cambridge University Press.

O'Neill, Saffron, and Sophie Nicholson-Cole. 2009. “"Fear won't do it»: Promoting positive engagement with climate change through visual and iconic representations". Science Communication 30: 355, DOI: 10.1177/1075547008329201

Smith, Nicholas, and Helene Hoffe. 2012. "How the public engages with global warming: A social representations approach". Public Understanding of Science 22 (1): $16-32$.

UNDP. 2017. National and Regional Human Development Reports. Human Development Report 2016. Accessed April 20, 2017. URL: http://hdr.undp.org/es/country-reports

Wachholz, S.; Artz, N.; and Chene, D. 2014. Warming to the idea: University students' knowledge and attitudes about climate change, Int. J. Sustain. High Educ., 15 (2) (2014), pp. 128-141.

Wagner, Wolfgang, Nicky Hayes, and Fátima Flores Palacios. 2011. El discurso de lo cotidiano y el sentido común. La teoría de las representaciones sociales. Barcelona: Anthropos. 